\title{
Reflexões sobre o potencial das políticas públicas democrático- populares locais para estudar possibilidades de um novo organi-
} zar

\section{Refletions on the potencial of local democratic-popular public policies in order to study possibilities of a new organizing}

Bruno César Santos de Alcântara ${ }^{1}$

\begin{abstract}
Resumo
Este artigo é fruto do esforço de um estudante com formação em administração, a partir de seus primeiros contatos mais esclarecidos com alguns sentidos da palavra política. $O$ entendimento desses sentidos o fez compreender, primeiro de tudo, o fazer pesquisa em administração como algo não asséptico (com implicações no mundo real) e, como contribuição para o tema central deste artigo, o desembocar disso numa opção de pesquisa que busca descobrir outras práticas de organizar em políticas públicas locais. Este artigo foi construído ao mesmo tempo em que seu autor refletia sobre como construir um projeto de pesquisa que se concretizará em sua dissertação. Foi a partir de reflexões que o permeiam que seu autor pôde ver a política pública municipal de esporte e lazer de Recife como um rico objeto de pesquisa no campo dos estudos organizacionais, em vista de se descobrir outras possibilidades de organizar. Ademais este artigo busca estimular o debate e mais reflexões de como os estudos organizacionais podem contribuir para a construção de uma sociedade verdadeiramente democrática no Brasil, ao mesmo tempo em que se reaproxima da própria política.
\end{abstract}

Palavras-chave: políticas públicas; práticas de organizar; democracia.

Abstract

This work is a result of the effort of a student graduated in Administration, from his first mature encounters with some senses of the political word. His understandings of these senses made him realize, firstly, the researching in Administration as something not aseptic (with implications to the real world) and, as a contribution to the central subject of this work, the flowing of that into an option of research, which seeks to find other practices of organizing in local public policies. This work was written while its author was thinking how to write a research project that will come true in his dissertation. The reflections presented in this work made possible for its author to see sport and leisure municipal public policies of Recife as a rich object of research in the field of organization studies in order to discover other possibilities of organizing. Besides, this work seeks to stimulate the discussion and more reflections on how organization studies can contribute to the construction of a truly democratic society in Brazil while it reencounters with politics.

Key words: local public policies; practices of organizing; democracy.

\footnotetext{
Mestrando do Programa de Pós-graduação em Administração da Universidade Federal de Pernambuco (PROPAD/UFPE). Endereço: Av. Prof. Moraes Rêgo, 1235 - Cidade Universitária - Recife - Pernambuco - Brasil - CEP: 50670-901. E-mail: bruno_alcan@yahoo.com.br

Artigo recebido em julho de 2006 e aceito para publicação em outubro de 2006
} 


\section{Introdução}

O desenvolvimento de uma consciência crítica que permite ao homem transformar a realidade se faz cada vez mais urgente. Na medida em que os homens, dentro de sua sociedade, vão respondendo aos desafios do mundo, vão temporalizando os espaços geográficos e vão fazendo história pela sua própria atividade criadora.

\section{Paulo Freire em Educação e mudança}

Este artigo é fruto do esforço de um estudante com formação em administração, a partir de seus primeiros contatos mais esclarecidos com alguns sentidos da palavra política. Esse beber dos entendimentos da política o fez compreender, primeiro de tudo, o fazer pesquisa em administração como algo não ascético (com implicações no mundo real) e, como contribuição para o tema central deste artigo, o desembocar disso numa opção de pesquisa que busca descobrir outras práticas de organizar em políticas públicas locais. Dessa maneira, faz reflexões numa tentativa de contribuir para os debates sobre a construção de uma sociedade efetivamente democrática no Brasil.

Isso se torna pertinente, primeiro, por trazer discussões sobre a fragilidade de nossa democracia, tanto como forma de governo quanto de sociedade, e sobre qual o papel dos estudos organizacionais nesse debate. No plano teórico/acadêmico, torna-se importante quando permite pensar sobre outras práticas de organizar refletindo sobre o papel das políticas públicas locais na construção de uma verdadeira democracia em nosso país.

Dessa maneira, no plano teórico-empírico, tenta-se uma contribuição para um fazer acadêmico não estéril, trazendo para o debate dos estudos organizacionais temas que preocupam o autor deste artigo como cidadão. É uma opção política de pesquisa. É também um esforço de se retomar o elo entre gestão pública (administração) e política pública (política), que vem se perdendo por uma opção política da academia brasileira em administração, como nos alerta Misoczky (2004).

Este artigo foi construído ao mesmo tempo em que seu autor refletia sobre como construir um projeto de pesquisa que se concretizará em sua dissertação. Foi a partir de reflexões que o permeiam que seu autor pôde ver a política pública municipal de esporte e lazer de Recife como um rico objeto de pesquisa no campo dos estudos organizacionais, em vista de se descobrir outras possibilidades de organizar.

Vale salientar que falar de política aqui não é abordar as assimetrias de poder nas organizações, mas tratá-la como um tema que permeia o cotidiano de uma sociedade, sem a ilusão que é algo distante de nós. A política está em cada ato do ser humano que tem repercussões em outros seres humanos. Todas as decisões que tomamos são políticas, pois elas decidem rumos, mudam nossa forma de ver as relações humanas, estão a favor de determinados interesses e, principalmente, fazem-nos refletir sobre nosso estar no mundo. Até quando se fala que não se é político, faz-se política, toma-se uma posição.

Quando se aborda política, é comum se referir ao "significado de governo, entendido como direção e administração do poder público", a algo que deve ser realizado "por especialistas (os administradores) e profissionais (os políticos), pertencentes a um certo tipo de organização sociopolítica (os partidos), que disputam o direito de governar, ocupando cargos e postos no Estado"; e derivado do sentido anterior, vê-se a política como uma "conduta duvidosa, não muito confiável, um tanto secreta, cheia de interesses particulares dissimulados e freqüentemente contrários aos interesses gerais da sociedade." (CHAUI, p.347).

Essa pequena descrição mostra que o conflito de sentidos permeia os entendimentos da política. Esse processo de "disputa" de entendimentos é o que faz dela um conceito rico para análises teóricas, principalmente, no campo dos estudos organizacionais, em que grande parte das abordagens teórico-metodológicas tenta naturalizar o consenso de conceitos como algo benéfico para as reflexões desse campo de estudos. 
Mais uma vez utilizando-se dos ensinamentos de Chaui (2004, p.348), o autor deste artigo descobre que a raiz histórica da palavra política é grega, vem de pólis. Pólis é a cidade como um espaço físico, formada por cidadãos que são homens livres e iguais, nascidos em um território. São assim, portadores de dois direitos inquestionáveis, a isonomia (igualdade perante a lei) e a isegoria (igualdade no direito de expor e discutir em público opiniões sobre ações que a cidade deve ou não deve realizar). Surge a primeira indagação: isso não faz lembrar os atuais discursos sobre democracia participativa em nosso país? Pois é, isso parece mostrar como as idéias são recorrentes.

Já que este artigo faz uma reflexão sobre a construção da democracia no Brasil, é importante retomar resumidamente a origem grega do que hoje se conhece desse regime político.

A invenção da política na Grécia tem como um de seus aspectos fundamentais a divisão territorial das cidades. Em Atenas, a pólis foi subdividida em unidades sociopolíticas ou demos. Assim, quem nascesse num demos, independentemente da situação financeira, tinha assegurado o direito de participar direta ou indiretamente das decisões da cidade. Quem nascesse no demos tinha o direito de participar diretamente do poder; por isso o nome do regime ser democracia. Lembrando que estavam excluídos escravos e mulheres.

Assim, algumas inquietações do autor permeiam a construção deste artigo. São elas: será que as experiências de democracia participativa no Brasil não são uma volta ao ideal grego de democracia? Será que não está seguindo o ideal da pólis? Será que uma apropriação contemporânea da ágora pode (des)considerar as desigualdades econômicas (materiais) de nossos cidadãos?

Os gregos (assim como os romanos) inventaram a política para: 1) separar a autoridade pessoal privada do chefe de família (privado) do poder impessoal público, que pertence ao coletivo; 2) separar autoridade militar e poder civil, com a primeira subordinando-se ao segundo; 3 ) separar "autoridade mágico-religiosa e poder temporal mágico, impedindo a divinização dos governantes"; 4) criar a idéia e a prática da lei como expressão de uma vontade coletiva e não da vontade pessoal do governante; 5) criar instituições e funções públicas para aplicar leis e garantir direitos; 6) criar os bens e recursos que pertencem à sociedade, o erário público; 7) criar o espaço político ou público (a Assembléia grega). É nesse último ponto que se vê o coração da invenção da política, pois dá oportunidade aos que têm direito à vida cidadã, de discutirem, deliberarem e decidirem sobre os rumos de suas respectivas sociedades. Além disso, "a política traz a prática da publicidade, isto é, a exigência de que a sociedade seja informada, conheça as deliberações e participe da tomada de decisão." (CHAUI, 2004, p.351-352).

Para reforçar a importância da invenção da política para a humanidade, nada melhor que retratar o seu sentido. Como afirma Chaui (2004, p.352, grifos meus),

[...] a política é inventada de um modo que, a cada solução encontrada, um novo conflito ou uma nova luta podem surgir, exigindo novas soluções. Em lugar de reprimir os conflitos pelo uso da força e da violência das armas, a política aparece como o trabalho legítimo dos conflitos, de tal modo que o fracasso nesse trabalho é a causa do uso da força e da violência.

Procurarei a partir de agora discutir a construção da democracia no Brasil com base em um panorama histórico geral, enfatizando o quanto é importante, não só como forma de governo, mas também de sociedade. (Re)inventar a democracia em nosso país também deve ser papel da academia em administração. Porém, essa reflexão não pode ocorrer nas mesmas bases epistemológicas que fazem da abordagem funcionalista a que predomina na área. Primeiro de tudo, é preciso aproximar-se de outras fontes das ciências humanas e sociais. Este artigo faz um esforço nesse sentido e procura discutir política e democracia no campo dos estudos organizacionais, campo que vem fazendo um esforço significativo para se pensar sobre outras práticas de organizar o mundo com abordagens teóricas e metodológicas interdisciplinares necessárias a esse tipo de esforço. 


\section{Relação Estado/sociedade no Brasil e a emergência do governo local}

A figura do Estado é tomada neste artigo a partir do governo populista de Vargas (anos 1930). O governo Vargas marca o que hoje conhecemos como modelo tradicional de administração pública; ou seja, caracterizado por ser "[...] centralizador, baseado no legalismo das prerrogativas do Poder Executivo, e que é marcado pela prática política autoritária, clientelista e patrimonialista.” (TAVARES, 2004, p.66).

Essas características refletem o Estado pai, que resolve todos os males da população, criando empregos ou estimulando sua criação, formulando e executando leis, determinando e recolhendo impostos e provendo educação, saúde, transporte e saneamento básico (infra-estrutura). O cidadão, dessa perspectiva, exerce sua cidadania predominantemente por meio do voto (democracia representativa) e faz de seu representante o reivindicador (ícone ou Messias) de suas aspirações. No entanto, seu representante, como a história nos mostra, não consegue separar sua função pública do uso dessa função para objetivos particulares (ou seja, o patrimonialismo). Quebra assim um dos principais traços do que os gregos e romanos propuseram quando inventaram a política.

Esses aspectos (não se pode deixar de considerar também nossa herança colonial), que caracterizam a formação do Estado brasileiro, contribuíram para que não desenvolvêssemos uma cultura política de reivindicação para conquistar uma maior participação na formulação das políticas públicas de nosso país. Predominou a espera de que os governantes solucionassem todas as crises que surgiam (e surgem).

Apesar dessa herança, não se pode esquecer que os movimentos sociais tiveram importante papel na luta pela democratização da sociedade brasileira. Cardoso (2004) demarca duas fases importantes de atuação dos movimentos sociais no Brasil. A primeira, na década de 1970, caracteriza-se pela "emergência heróica dos movimentos sociais", que surgem de forma espontânea para substituir os instrumentos de participação fechados no período de repressão (ditadura militar). O Estado era visto como inimigo. A segunda, nos primeiros anos da década de 1980, quando há a institucionalização dos canais de participação e diálogo com o Estado, de modo que, em alguns casos, as relações diretas estabelecidas entre os movimentos e as agências públicas criaram novas possibilidades de cooptação.

Mesmo assim, o Estado se estabeleceu em um paradigma tecnocrático, em que as decisões sobre as políticas públicas ficaram subordinadas ao quadro técnico do governo, que toma as decisões com base apenas em critérios racionais e técnicos, sem levar em consideração as necessidades e heterogeneidades básicas da sociedade ou os conflitos que são inerentes ao mundo da política (DINIZ, 1997).

Somente nos anos 1980, por influência externa da crise financeira do Estado do bem-estar social, juntamente com a ascensão de governos conservadores na Inglaterra e nos Estados Unidos, o Estado brasileiro passa a rever seu aparato institucional. Porém, mesmo com a expectativa em torno de projetos sociais, criada com a ascensão da Nova República (redemocratização), o Estado brasileiro ainda deu ênfase aos planos econômicos. Como afirma Tavares (2004, p.65, grifos meus),

[...] o Brasil optou pelas medidas provisórias do Executivo. As decisões políticas foram tomadas com total liberdade, sem consulta e sem transparência, por pequenos grupos isolados nos gabinetes ministeriais. Ou seja, as decisões se pautaram pela legalidade dos atos e não pela legitimidade das ações $[\ldots]$.

A Constituição Federal de 1988 traz a prerrogativa legal da descentralização administrativa e a instauração de mecanismos de exercício da democracia direta. Dessa maneira, abre-se espaço, nos anos 1990, para o início de processos que ensejam uma maior participação da sociedade nas decisões políticas por meio, principalmente, das esferas públicas não-estatais. Busca-se superar o modelo tradicional de gestão, que vinha (e de alguma forma ainda vem) caracterizando historicamente a administração pública brasileira, e iniciar um processo de construção de uma gestão "mais" democrática da "coisa" pública. 
É um esforço para flexibilizar a burocratização do aparato estatal e aproximar-se mais das realidades locais de cada região e de suas respectivas populações. O cidadão não tem somente que reivindicar seus direitos. Abre-se um canal entre governantes e governados para a participação ativa destes na formulação de políticas públicas que o afetam. Um canal maior de diálogo surge na relação sociedade/Estado. Esse canal é marcado por um espaço de negociação e conflito que redefine o que é interesse público.

A partir desse debate que se trava nos anos 1990, busca-se superar o modelo tradicional de nosso Estado, centralizador, autoritário e verticalizado em suas relações de poder com a sociedade. Assim, afirma Tavares (2004, p.67, grifos meus),

no novo cenário que se desenha, os municípios assumem uma importância cada vez maior; as cidades assumem um papel central na sociedade, e a construção da capacidade de governo local tornou-se fundamental.

Como afirma Dowbor (1998a, p.353), "na sociedade que desponta para o terceiro milênio, mais capacidade de governo significará maior capacidade de gestão e de decisão política na própria base da sociedade". É antes de qualquer coisa, "o resgate da capacidade política do cidadão." (DOWBOR, 1998a, p.356).

Dowbor (1998a) fala de um novo paradigma de Estado, nele entram características como: "menos Estado, e mais setor público", descentralização, redes horizontais, governança, controle social e democratização da informação. Nele, a participação social nas decisões políticas é central. O debate sobre um novo paradigma surge num momento no qual se percebe a fragilidade dos partidos políticos em representarem seus ideais e os de seus partidários. Dowbor (1998a, p.364), então, afirma que "a democracia apoiada num só pé, no partido, tornou-se insuficiente".

A crise de representação da sociedade no Estado, as conseqüências da urbanização tardia de nosso país e as prerrogativas legais abertas pela Constituição de 1988 abrem espaço para que as discussões em torno dos interesses do cidadão cheguem à sua porta. Em termos de política de governo, inicia-se, no fim da década de 1980, com a implantação do orçamento participativo em Porto Alegre e os debates que se seguem na década de 1990 sobre o potencial dos espaços públicos não-estatais, um novo caminho sobre como devem se estabelecer as relações entre Estado e sociedade no Brasil, que desemboca no debate de como deve ser estabelecida a democracia (ou as democracias) em nosso país.

Dowbor (1998b, p.377) afirma que

é indispensável que o nível local de poder, [...], esteja no leme do processo. É a única instância onde podem ser efetivamente articuladas as políticas de saúde, de educação, de formação profissional, de emprego, de informação, uma ação reforçando a outra.

Nessa interpretação, acredita-se que no nível local as necessidades da população podem ser melhor diagnosticadas, a comunidade tem a oportunidade de decidir o que é melhor para o coletivo e as decisões podem se tornar mais simplificadas e menos onerosas, aumentando a efetividade das políticas públicas e a sua capacidade de atender à heterogeneidade de demandas da nossa sociedade. Além disso, tem o potencial de fazer o cidadão exercer a política.

\section{(Nova) relação Estado/sociedade? (Novas) concepções em disputa}

O que está posto em causa nesta discussão é a perda de legitimidade da democracia representativa, que faz do insulamento burocrático, da centralização, do autoritarismo e da falta de controle social ativo por parte do cidadão (além voto) as características principais da ação estatal; ou seja, a perspectiva conservadora da relação Estado/sociedade. 
A partir da Constituição de 1988, os espaços públicos não-estatais ganham centralidade e com isso a participação da sociedade civil na administração pública. Essa mudança legal exige do aparato estatal uma mudança estrutural, política e cultural. Da sociedade exige-se uma nova cultura política, à medida que precisa reivindicar um espaço legítimo de participação na formulação das políticas públicas que lhe são destinadas.

Nesse contexto, ganham proeminência os novos movimentos sociais em detrimento da perda de prestígio (crise do paradigma pluralista de representação do sistema político brasileiro) dos partidos políticos. Por trás desse processo está a perda de legitimidade do Estado, pois "os cidadãos não se reconhecem mais nas instituições que, por definição, foram por eles criadas." (VIEIRA, 1999, p.248).

Como salienta Diniz (1997, p.196, grifos meus),

as novas condições internacionais e a complexidade crescente da ordem social pressupõem um Estado dotado de maior flexibilidade, capaz de descentralizar funções, transferir responsabilidades e alargar, em lugar de restringir, o universo dos atores participantes, sem abrir mão dos instrumentos de controle e supervisão.

Muitas das características que foram destacadas no parágrafo anterior, assim como boa parte dos autores que são mencionados nesta seção do artigo e na anterior têm um viés mais liberal do que seja a administração pública. Dowbor (1998a, 1998b), por exemplo, muitas vezes deixa dúvidas se está querendo transpor para a gestão local os modelos gerenciais do mundo da administração, que não consideram a dimensão política. Poder e conflito nessa perspectiva são vistos como disfunções. Além disso, esses tipos de argumentos permitem questionar se priorizar a perspectiva liberal na construção da democracia no país não é propor um novo modelo de administração pública. O próprio uso de palavras como paradigma, flexibilidade e descentralização faz atentar para o perigo de se tratar o processo de construção de uma relação efetivamente democrática entre Estado e sociedade como se estivesse aplicando um modelo de gestão em uma empresa.

Alguns dos autores já mencionados, como Diniz (1997) e Dowbor (1998a, 1998b), estão imbuídos do sentido liberal dos direitos. Direitos que foram conquistados, criados e construídos por nações que hoje governam o mundo. Assim, muitas vezes "[...] ignoram as particularidades históricas e culturais [das sociedades latinoamericanas], sua heterogeneidade estrutural [...]", ao pensar nosso continente a partir dos "padrões de referência da experiência liberal européia." (LANDER, 1999, p.479).

Reforçando esse tipo de visão, ainda que num primeiro olhar dê a entender que rompe com a herança da visão de cidadania do Estado burguês, temos, por exemplo, Vieira (1999, p.252, grifos meus). Para ele

é a cidadania que fornecerá o elã vital para a criação de uma nova institucionalidade política, onde a sociedade civil cumprirá papel central na construção de um espaço público democrático, única fonte possível de governabilidade e legitimidade do sistema político.

Nessa perspectiva, o autor veste-se da interpretação liberal dos direitos para afirmar que é fundamental superar a visão liberal e, assim, o "modelo do cidadão patriota proposto para toda a sociedade, como se ela fosse homogênea e unidimensional." (VIEIRA, 1999, p.250). Isso mostra a necessidade de se refletir sobre que tipo de cidadania se pretende construir no Brasil quando se luta por uma sociedade verdadeiramente democrática.

Nos debates sobre a relação Estado/sociedade no Brasil, após a Constituição de 1988, percebe-se que além de cidadania ganham relevância conceitos como: espaço público não-estatal, participação, descentralização, inclusão social, controle social, governança e governabilidade, entre outros.

Diante da impossibilidade de abordar todos eles neste artigo, adota-se a partir de agora o conceito de cidadania na acepção de Dagnino (2004). Essa escolha permite abordar as dimensões da cultura e da política como "nexo constitutivo". Dimensões essas extremamente desafiadoras para que se consolide um regime político efetivamente democrático no Brasil. Já que quando se discute sobre a construção democrática em nossa sociedade, o tema de uma nova cultura política emerge. Como afirma Dagnino (2004, p.104, grifos meus), a nova noção de 
cidadania "organiza uma estratégia de construção democrática, de transformação social, que afirma o nexo constitutivo entre as dimensões da cultura e da política".

Considerando as raízes autoritárias e profundas desigualdades sociais do Brasil, há uma necessidade de posições mais radicais e transformadoras, quando se trata de construção democrática. Dagnino (2004) traz um novo alento ao debate de conceitos sobre cidadania, ou para parafraseá-la, "uma nova noção de cidadania". Parece fugir do viés liberal dos autores anteriores. Essa discussão vai além do debate da democracia como regime de governo. Sua preocupação é contribuir para que a sociedade brasileira construa a democracia em seu cotidiano.

No início da década de 1990, o Brasil estava num momento em que surgia a primeira experiência governamental com base na participação social, a prefeitura de Porto Alegre. Ao mesmo tempo, uma reforma gerencial do Estado estava em vias de ocorrer. Nesse contexto, o trabalho de Dagnino (2004), permeado pela defesa das novas formas de relação Estado/sociedade, dá relevância à necessidade de uma mudança cultural em nossa sociedade, dada às novas oportunidades para o país construir uma cultura democrática em suas relações. Via na ampliação do espaço da política uma "estratégia que reconhece e enfatiza o caráter intrínseco e constitutivo da transformação cultural para a construção democrática". A construção da nova noção de cidadania seria o caminho para a "construção e difusão de uma cultura democrática." (DAGNINO, 2004, p.104).

Apesar de ter defendido a construção de uma cultura democrática, Dagnino (2004) não deixou de reconhecer as desigualdades econômicas e a exclusão social presentes no país, inclusive, um problema que se estende para a América Latina. No entanto, dava centralidade à questão cultural, para que pudéssemos superar nossos problemas, pois lhe parecia evidente o vínculo entre o autoritarismo social de nossa cultura e o quadro de miséria a que tínhamos chegado (e em que ainda nos encontramos). No entanto, a transformação dessa realidade não seria por mudanças nas bases econômicas da sociedade brasileira.

Retratando a importância de se olhar a cidadania como uma construção ou "Estratégia Política", a autora compreende esse conceito central da democracia como um processo que está sendo construído em uma disputa entre Estado e sociedade, não como um conceito dado (estrutural). Como ela mesma expõe,

afirmar a cidadania como estratégia significa enfatizar o seu caráter de construção histórica, definida portanto por interesses concretos e práticas concretas de luta e pela sua contínua transformação. Significa dizer que não há uma essência imanente ao conceito de cidadania, que o seu conteúdo e seu significado não são universais, não estão definidos e delimitados previamente, mas respondem à dinâmica dos conflitos reais, tais como vividos pela sociedade num determinado momento histórico. Esse conteúdo e significado, portanto, serão sempre definidos pela luta política. (DAGNINO, 2004, p.107, grifos meus)

Essas palavras de Dagnino aumentam o dilema em se refletir e depois se tomar uma posição em favor de uma transformação social no país, no que se refere não somente à democracia como forma de governo, mas também como forma de sociedade. A partir disso, como concretizar sua proposta de uma nova noção de cidadania? Como construir e concretizar novos entendimentos sobre política em nossa sociedade? Como criar práticas (de organizar) sociais que concretizem uma nova cultura política em nosso país? Essas são questões que os estudos organizacionais precisam responder, tendo vista contribuir para que nossa sociedade torne-se efetivamente democrática.

Parte-se, então, para as seções do artigo em que as reflexões do autor têm maior liberdade. A pretensão é suscitar debates e inquietar o leitor. A seguir, procura-se discutir por que se dá ênfase à cultura política nos debates envolvendo gestão pública e democracia no Brasil. 


\section{Por que a insistência no debate sobre a necessidade de uma nova cultura política em nosso país?}

Trabalhos que tratam da relação Estado/sociedade, a partir do início dos anos 1990, principalmente os que abordam o conceito de cidadania, como o de Dagnino (2004) e o de Vieira (1999), enfatizam como grande desafio da democracia a falta de cultura política de nossa sociedade. Essa perspectiva também pode ser encontrada em Telles (2004, p.93, grifos meus), quando afirma que é "[...] no jogo das ambivalências inscritas na vida social [brasileira], que a questão da cidadania se define como problema - problema teórico, problema histórico, problema político [...]". Nesse sentido, a necessidade de uma mudança cultural, tanto da sociedade, em geral, como dos políticos (incluindo os gestores públicos), em particular, em torno da importância da política para a construção de uma sociedade democrática é enfatizada e motivo de debates.

No intuito de desencadear uma mudança cultural dessa magnitude no Brasil, alguns governos estaduais e municipais, principalmente os de centro-esquerda, vêm lançando mão de experiências "mais" democráticas de administração pública. Estas procuram levar em consideração a "voz do povo", o diálogo entre os vários setores organizados da sociedade, o cidadão comum e o político, em termos das prioridades e da formulação de políticas públicas locais. Os orçamentos participativos, experiência de governos municipais do Partido dos Trabalhadores (PT), são emblemáticos nesse processo.

É evidente que a construção de uma nova cultura política não acontece em apenas uma ou duas décadas. A tradição autoritária, clientelista, centralizadora e patrimonialista que caracteriza não só nossas formas de governos, mas também as relações sociais em nossa sociedade, é resquício da própria colonização do Brasil, reforçada ainda pelos períodos populista e da ditadura; ou seja, ainda se tem muito pouco tempo de experiência verdadeiramente democrática no Brasil.

Reconhece-se que o período de novas experiências de governos democráticos ainda é muito curto. Por isso, conclusões precipitadas sobre essas novas experiências de gestão pública estão suscetíveis a erros. Disputas, lutas, debates, resistências e análises acontecem e estão por vir, e dessa maneira os seres humanos constroem sua história. Precisamos construir primeiro nossa história política, e de alguma forma isso se realiza. Mas precisaremos nos perguntar, constantemente, se estamos no leme desse processo ou se é um modelo de fora que rege o caminho do Brasil em direção a uma sociedade efetivamente democrática. Antes de tudo, é preciso repensar se realmente enfatizando a perspectiva cultural, haverá condições para que nossa sociedade conquiste seus direitos e exerça política.

$\mathrm{Na}$ "pólis" em que vivemos, as desigualdades econômicas não podem ser desconsideradas. Retomar o sentido de política e democracia grego exige uma reconstrução desses conceitos em nosso tempo e em nossas realidades (um país continental e assolado por desigualdades econômicas e diferenças sociais). Assim, parece claro que não se pode, no Brasil, discursar que independentemente da situação financeira e da capacidade técnica e política de cada cidadão todos têm assegurado o direito de participar direta ou indiretamente das decisões de sua cidade. Ou, que para participar diretamente do poder, basta somente nascer em um território de direitos como no demos da pólis grega.

Essas são inquietações que acompanharam o autor na construção deste artigo e espera-se que o acompanhem ao longo de sua vida de pesquisador-cidadão. O desafio para uma verdadeira democracia no país é muito grande e se reconhece, aqui, a dificuldade de alguns autores brasileiros em sair da insistência no aspecto cultural para que se consiga uma transformação da realidade social e política do país.

\section{A influência do ideal grego nos debates sobre a construção de uma nova relação Estado/sociedade no Brasil}

Aqui, são trazidas algumas inquietações do autor ao perceber a influência das idéias de Jürgen Habermas na literatura brasileira sobre gestão pública. Para o autor deste artigo, essa influência faz os autores brasileiros priorizarem a perspectiva cultural quando se discute sobre política e democracia no país. Evidente que não é a in- 
fluência das idéias de Habermas em si que traz inquietações ao autor. O prevalecer da visão cultural sobre a da política, como também a anulação desta por aquela, é uma de suas principais inquietações.

Longe de ter respostas conclusivas, é pertinente trazer, em resumo, algumas idéias de Habermas que influenciaram construções teóricas de autores brasileiros sobre o potencial do espaço público na construção de uma sociedade efetivamente democrática no país. Assim como os gregos, Habermas, com sua teoria da ação comunicativa, desconsidera as bases materiais e com isso contribui para que voltemos à ênfase na perspectiva cultural de análise.

Sabe-se que, com o processo de modernização (racionalização) da vida em sociedade, a razão técnica ou instrumental passou a predominar nas relações sociais sobre outras formas de racionalidade existentes. Nesse contexto, ciência e tecnologia tornam-se a expressão mais sofisticada do império da razão. Habermas, em busca de uma saída para o pessimismo da modernidade, propõe sua teoria da ação comunicativa e afirma que, além da razão instrumental, existe nas relações sociais a razão comunicativa. Esta se baseia na linguagem, que se expressaria na busca do consenso entre os indivíduos por meio do diálogo (VIEIRA, 1999).

A razão comunicativa é a que está presente no cotidiano do "mundo da vida", formado pela cultura, sociedade e personalidade. A razão instrumental é a que predomina no "sistema", formado pelas esferas da economia e da política (Estado), que com o processo de modernização capitalista dominou e colonizou o mundo da vida (VIEIRA, 1999). O que Habermas vai propor, então, é a luta pela "independência" ou autonomia do mundo da vida diante do sistema, por meio da lógica dialogal da ação comunicativa.

Tanto o mundo da vida como o sistema são atravessados por dimensões do público e do privado. Para o propósito deste artigo, vale destacar a parte pública do mundo da vida, que é a participação política do cidadão. Esta ganha centralidade na análise dos espaços públicos. O espaço público, autônomo e permeado pela razão comunicativa, é visto como local de disputa entre discursos e no qual "se realiza a interação intersubjetiva de cidadãos conscientes, solidários e participativos." (VIEIRA, 1999, p.228, grifo meu). Repudiando a visão liberal de cidadania,

a autonomia do espaço público participativo revaloriza o primado da comunidade e da solidariedade, possibilitando a libertação da sociedade civil dos imperativos sistêmicos, isto é, dos controles burocráticos do Estado e das imposições econômicas do mercado. (VIEIRA, 1999, p.229, grifos meus)

Assim, "a esfera pública atua como instância intermediadora entre os impulsos comunicativos gerados na sociedade civil (no 'mundo da vida') e as instâncias que articulam, institucionalmente, as decisões políticas (parlamento, conselhos)". (VIEIRA, 1999, p.249, grifos meus).

Evidente que não se pode deixar de reconhecer a contribuição de Habermas ao debate sobre a vida política de uma sociedade, principalmente, no que se refere à sua maneira de ver a relação Estado/sociedade como um sistema de eclusas, em que os influxos comunicativos da sociedade civil influenciam as instâncias decisórias (o Estado) (VIEIRA, 1999). Esse tipo de compreensão pode ser rico para o caso brasileiro, pois o Estado é conhecido historicamente pelo seu insulamento burocrático e postura autoritária (potencial para a cooptação). No entanto, não se deve esquecer que a construção teórica de Habermas tem subjacente uma sociedade emancipada materialmente e em termos subjetivos, o que não é o caso do Brasil.

Mesmo com as experiências da democracia participativa por meio dos orçamentos participativos, falta conteúdo nos discursos de nossa população para reivindicar e decidir sobre suas necessidades mais prementes nos espaços públicos que se abrem. Por exemplo, ao considerar o espaço público como algo autônomo às desigualdades de ordem econômica (sistema), como propõe Habermas, em que independentemente do conteúdo da linguagem todos têm direito a falar, estamos transpondo para nossa realidade o sentido de política que foi importante para uma determinada sociedade em determinado momento histórico. Dessa maneira, podemos cair na armadilha de transformar nossos espaços públicos de participação social em uma espécie de ágora ateniense. 
Como mostra Dagnino (2002), a falta de qualificação técnica específica e política dos representantes da sociedade civil faz com que estes estejam em total desvantagem diante dos representantes governamentais, nas disputas e debates que ocorrem nos espaços públicos não-estatais. Além disso, enfrentamos ainda resquícios do autoritarismo que caracteriza historicamente o Estado brasileiro. Outro problema levantado pela autora, é que a busca por maior qualificação técnica e política por parte da sociedade civil cria problemas entre luta institucional e mobilização social. A busca de qualificação faz com que a luta aconteça dentro do "sistema" e não tanto no "mundo da vida"; ou seja, a mobilização social perde força e a possibilidade de cooptação aumenta. A autonomia de nossa esfera pública (do mundo da vida) ainda está longe de ser alcançada (se é que será), apesar de algumas iniciativas bem-sucedidas no país com a implementação do orçamento participativo, por exemplo, em Porto Alegre e em Recife. Este precisará ainda de certo tempo para a análise de seu efetivo desprendimento das características centralizadoras, autoritárias e não participativas que caracterizaram a relação entre Estado e sociedade e a formulação das políticas públicas no Brasil.

Como fazem observar Amantino-de-Andrade e Arenhart (2005), outro grande problema das experiências com participação da sociedade na formulação de políticas públicas é a falta de compreensão, tanto dos gestores públicos como da população, do que são os princípios democráticos e de participação social.

Levantam-se, então, as seguintes questões: será que ainda acreditamos numa espécie de ágora grega para construir uma sociedade democrática? Será que se prioriza a perspectiva cultural exatamente porque ainda tem-se a "ilusão" de trazer o ideal grego de política e democracia para nossa realidade, ou porque se considera que a origem do problema da democratização no país é de ordem cultural?

Para o autor deste artigo é preciso refletir sobre isso, pois se se parte da identificação e formulação equivocada de um problema, fica-se sempre atrás de soluções também equivocadas. Será que a tentativa de voltar ao passado não é romantizar uma solução para um problema presente, como fizeram os socialistas utópicos, que propunham voltar ao passado como solução para os problemas que viviam no presente (no hoje) deles?

Para o campo da administração o desafio é refletir sobre a democracia em bases materiais, num complemento às reflexões sobre a necessidade de uma (nova) cultura política em nossa sociedade. Mas, como refletir sobre a democracia em bases materiais?

O autor deste artigo vê em perspectivas teórico-empíricas que estão procurando outras possibilidades de organizar, que não aquelas que têm como base a organização burocrática, um rico caminho para se pensar outras práticas de organizar nos estudos organizacionais. Já que aqui a preocupação é com a (re)construção de uma sociedade verdadeiramente democrática em nosso país, um campo empírico que parece profícuo nesse sentido é o das políticas públicas democrático-populares locais. Assim, ao mesmo tempo em que se pensa em um novo organizar, se contribui para que os estudos organizacionais vislumbrem outras alternativas de práticas de organizar para que a democracia torne-se efetivamente tanto forma de governo como de sociedade no Brasil.

\section{Reflexões em vista de uma opção de pesquisa}

No Brasil, o Estado tem ainda grande papel na mudança de sua relação com a sociedade, tendo em vista superar a centralização (insulamento) e a falta de diálogo que o vem caracterizando historicamente. Além desse papel, tem os seguintes: incentivar a participação da sociedade na formulação de políticas públicas; tornar prioridade políticas sociais estruturantes; não se restringir somente a reformas administrativas e técnicas de cunho neoliberal; qualificar não somente tecnicamente o gestor público, mas oferecer-lhe formação política e humana; utilizar-se cada vez mais da prerrogativa legal dos espaços públicos não-estatais, não como legitimador de suas decisões ou terceirização delas, mas como espaço de conflito e negociação do interesse público entre Estado e sociedade; descentralizar não somente as prerrogativas de decisão e formulação de políticas públicas locais, mas também um maior volume do orçamento aos estados e municípios. Uma nova maneira de relação Estado/sociedade pressupõe também a superação do autoritarismo de nossa cultura e a passividade de nossa forma 
de cidadania e, principalmente, a compreensão do que seja política por nossa população e, porque não, por nossos governantes, resultando em novas práticas políticas.

Todos esses desafios demandam um novo olhar ao organizar. Nesse sentido, como acadêmicos, precisamos refletir sobre algumas questões, entre elas: como pesquisadores, como fica nosso fazer político? Como a academia em administração pode contribuir para a construção de uma sociedade efetivamente democrática no Brasil? Quais os paradoxos na apropriação dos conceitos das ciências administrativas para a discussão de gestão, política pública e democracia em nossa sociedade? Como lidar com os modelos de gestão pública? A saída seria um modelo? Conceitualmente existe contradição quando falamos em gestão democrática de governo (alia consenso e conflito)? Não se pode esquecer que o princípio da política é a abertura para o debate e não a busca e o reforço do consenso, como ocorre no campo da gestão em sua vertente funcionalista.

Pede-se, então, aos leitores que pensem nas seguintes questões: é possível esse tipo de reflexão em administração? A administração tem que se preocupar com temas da sociedade (política, democracia e desigualdades sociais) ou somente da organização (gestão, eficiência e resultado)? É papel dos estudos organizacionais refletir sobre a democracia em bases materiais (práticas de organizar)? Os programas políticos das prefeituras progressistas são caminhos para pensar em outras práticas de organizar?

Para o autor deste artigo, a área de estudos organizacionais, especialmente no Brasil, tem papel nas respostas a alguns dos questionamentos aqui presentes, pois é dela também o papel de pensar sobre outras práticas de organizar em nossa sociedade.

A partir de um interesse particular pela área de esportes, percebi que alguns formuladores de políticas públicas, nomeadamente, na área de esporte e lazer da Prefeitura Municipal de Recife, trabalham com princípios e fundamentos norteadores de práticas em vez de modelos de práticas impostos à população. Dessa maneira, os princípios norteadores da política municipal de esporte e lazer são passíveis de transformação por aqueles a quem ela se dirige, não havendo imposição de um modelo de política pública. Essa perspectiva faz da prática cotidiana aspecto central da política. Assim, faz da construção histórica aspecto central de sua práxis. Mas será que suas práticas conseguem absorver o conteúdo transformador de seus discursos? Que mudança isso trará ao modo como se entende e faz política e se constrói democracia no Brasil? Há possibilidades de um novo organizar nessas experiências?

Nesse sentido, procurarei retomar o esforço crítico de autores como Alberto Guerreiro Ramos, Maurício Tragtenberg e Fernando Prestes Motta. Eles proporcionam um olhar contextualizado e apropriado a nossa realidade. Fazem-nos pensar os estudos organizacionais considerando as particularidades de nossa sociedade e das práticas de organizar que podemos construir. Dão os primeiros ensinamentos para quem se "arrisca" num caminho teórico-empírico que pensa em outras possibilidades de organizar. Seus trabalhos refletem a importância da sociologia, da educação, da ciência política, da economia, da filosofia, enfim, das ciências humanas e sociais, para que se possa refletir com mais propriedade sobre o papel dos estudos organizacionais em nossa sociedade.

As reflexões presentes neste artigo foram construídas à medida que seu autor se aproximava do campo das políticas públicas municipais de esporte e lazer, enfatizando sempre a experiência da prefeitura de Recife. Percebeu, então, que essa política poderia servir como objeto empírico para se refletir sobre outras possibilidades de organizar. Numa tentativa de contribuição para as reflexões sobre a democracia em bases materiais, analisará em seu trabalho de dissertação como os elementos transformadores do discurso político/programático da política de Recife se concretizam nas práticas de organizar de círculos populares de esporte e lazer. Dessa maneira, pretende descobrir novas práticas de organizar o mundo. Para isso, uma abordagem teórico-crítica de pesquisa precisa ser complementada por um novo olhar à realidade. Isso se traduz numa nova abordagem metodológica fundamentada em outras epistemologias e não mais no modelo de racionalidade da ciência moderna. Este, fundado na racionalidade positivista das ciências naturais, que se arvora senhora da compreensão da realidade em si, pressupondo uma correspondência entre pensamento e realidade, de maneira que nenhuma "construção" humana esteja presente. Modelo de ciência em que se busca uma linguagem natural (neutra), liberta do senso 
comum, para se legitimar, como se distante das influências da dinâmica social e política em que se insere. Além disso, privilegia os métodos quantitativos no seu modo de fazer ciência e de chegar a uma "verdade". Que, ademais, contribui para a naturalização da ordem vigente, isto é, o sistema capitalista (hegemonia do mercado) como única forma de organização social possível, e da burocracia como estratégia de administração. Fica claro que se a administração continuar privilegiando a visão dominante que rege seus pressupostos, ela estará "sob o risco de se tornar uma ciência vazia, desprendida da realidade social e presa a antigas referências locais e formais de análise.” (BRONZO; GARCIA, 2000, p.86).

Nesse sentido, a perspectiva construtivista precisa ser mais profundamente trabalhada no campo dos estudos organizacionais. Essa abordagem de pesquisa, em linhas gerais, defende que o ser humano não acha ou descobre conhecimento, mas sim o constrói ou o faz. Dessa maneira, inventamos conceitos, modelos e esquemas para dar sentido às novas experiências, sempre testando e modificando nossas construções à luz de novas experiências (SCHWANDT, 1994).

Em termos de análise e interpretação de dados, a análise crítica do discurso parece ser um caminho cheio de potencialidades para um trabalho que procura compreender como elementos transformadores de um discurso político se concretizam na prática. Fairclough traz importante contribuição nesse sentido, com sua teoria social do discurso. Ao considerar a linguagem como forma de prática social, vê no discurso "um modo de ação" com o qual as pessoas agem sobre o mundo e sobre outras pessoas. Esse discurso se relaciona dialeticamente com a estrutura social em que ocorre. Assim, "o discurso é uma prática, não apenas de representação do mundo, mas de significação do mundo, constituindo e construindo o mundo em significado." (FAIRCLOUGH, 2001, p.91).

Os trabalhos desse autor proporcionam a compreensão de uma relação que parece tão importante em administração quanto no exercício da política, qual seja, entre discurso e prática. Evidente que essa compreensão não pode se preocupar com a aplicação da teoria na prática, muito comum nas abordagens funcionalistas dos estudos organizacionais. O uso dos trabalhos de Fairclough é uma possibilidade de reflexão através de novas concepções do que seja discurso e prática, para então se pensar em novas concepções de praticar o organizar. Assim, uma proposta de pesquisa que pretende vislumbrar outras possibilidades de pensar nos estudos organizacionais não pode fugir do desafio de beber de outras ciências sociais, muito menos de adotar uma abordagem de análise de dados não muito usual no campo das ciências sociais aplicadas.

Essa não é uma preocupação isolada, já que há um conjunto de pesquisadores preocupados com outras possibilidades de organizar nos estudos organizacionais. Isso vem sendo realizado em estudos voltados à realidade local de alguns estados brasileiros e a temas e objetos empíricos menos fechados. Tenta-se assim fugir das correntes dominantes, que são aperfeiçoamentos do modo taylorista de "fabricar" o mundo. A própria maneira como foi concebido e organizado o último Eneo foi um esforço nesse sentido, isto é, uma nova prática de organizar nas discussões acadêmicas com esperanças de repercussões na maneira como a academia brasileira em administração vem organizando seus eventos.

Ademais, este artigo busca estimular debates e mais reflexões sobre como os estudos organizacionais podem contribuir para a construção de uma sociedade verdadeiramente democrática em nosso país, ao mesmo tempo em que se reaproxima da própria política. O próprio conceito de política dessa reaproximação deve ser motivo de debates e mais reflexões. O autor deste artigo dará continuidade a esse desafio na construção de sua dissertação de mestrado, que, como já mencionado, preocupa-se em analisar como os elementos transformadores do discurso político/programático de uma política pública se concretizam nas práticas de organizar de seus círculos populares de esporte e lazer. Nesse sentido, uma política pública municipal e seus diversos cenários, como espaços de construção de novas práticas organizacionais são centrais, exigindo um olhar pertinente a esse contexto.

Assim, diferentemente do que vem predominando nos estudos organizacionais, o caminho crítico de investigação adotado na proposta de dissertação do autor deste artigo se preocupa com o avanço de formas de organização e práticas gerenciais comuns ao mundo das empresas em outras realidades organizacionais. Procura então 
pensar em novas práticas de organizar, em organizações não pertinentes ao "enclave social do mercado", representando outros modos de organização com os quais os membros de uma sociedade cuidam "de tópicos substantivos de vida, na conformidade de seus respectivos critérios intrínsecos e no contexto dos cenários específicos a que esses tópicos pertencem", em outra "proposta de vida associada." (GUERREIRO RAMOS, 1989, p.178).

Espera-se encontrar, nos cenários de construção da política municipal de esporte e lazer da cidade de Recife, outro modo de pensar e executar práticas de organizar "fora dos limites da organização possível" (MISOCZKY; VECCHIO, 2004, p.12), assim como uma aproximação com práticas de organizar cotidianas, a princípio, mais substantivas.

É um mergulho em um conjunto de maneiras de organizar que, em um primeiro momento, parecem experimentar "formas não gerenciais de convivência" e que, além disso, estão situadas em nosso contexto de "formação social periférica." (MISOCZKY; VECCHIO, 2004, p.12). Em termos metodológicos, inova-se ao dar voz ao excluídos, no caso da pesquisa, às comunidades que concretizam os círculos populares de esporte e lazer em estudo. Nesses círculos, os consensos parecem temporários aos momentos participativos de construção da política, pois a comunidade exerce política, "[...] de um modo que, a cada solução encontrada, um novo conflito ou uma nova luta podem surgir, exigindo novas soluções." (CHAUI, 2004, p.352, grifos meus). É proposta da política de esporte e lazer da cidade de Recife conscientizar criticamente as comunidades da periferia sobre sua condição e de como podem, a partir da tomada dessa consciência, lutar por uma transformação de suas realidades sociais. Essa parece ser uma experiência rica de construção de uma sociedade efetivamente democrática e, ao mesmo tempo, parece contribuir para se pensar sobre outras possibilidades de organizar nos estudos organizacionais. 


\section{Referências}

AMANTINO-DE-ANDRADE, J.; ARENHART, A. J. Participación social en el Sistema Único de Salud: una utopía por cumplirse en municipios de pequeño porte del Valle del Taquari. In: MISOCZKY, M. C.; BORDIN, R.. (Org.). Géstion local de salud: prácticas y reflexiones. Porto Alegre: DaCasa/Opas, 2005. p.37-56.

BRONZO, M.; GARCIA, F. C. As bases epistemológicas do pensamento administrativo convencional e a crítica à teoria das organizações. In: RODRIGUEZ, S. B.; CUNHA, M. P. (Org.). Estudos organizacionais: novas perspectivas na administração de empresas (uma coletânea lusobrasileira). São Paulo: Iglu, 2000. cap.1, p.65-89.

CARDOSO, R. C. L. A trajetória dos movimentos sociais. In: DAGNINO, E. (Org.). Anos 90: política e sociedade no Brasil. São Paulo: Brasiliense, 2004. p.91-102.

CHAUI, M. Convite à filosofia. São Paulo: Ática, 2004.

DAGNINO, E.. Sociedade civil, espaços públicos e a construção democrática no Brasil: limites e possibilidades. In: (Org.). Sociedade civil e espaços públicos no Brasil. São Paulo: Paz e Terra, 2002.

Os movimentos sociais e a emergência de uma nova noção de cidadania. In: (Org.). Anos 90: politica e sociedade no Brasil. São Paulo: Brasiliense, 2004. p.103-118.

DINIZ, E. Em busca de um novo paradigma: a reforma do Estado no Brasil dos anos 90. In: lidade. Rio de Janeiro: Editora Fundação Getúlio Vargas, 1997.

DOWBOR, L. Estado e sociedade civil: a democracia participativa. In: A reprodução social: propostas para uma gestão descentralizada. Petrópolis: Editora Vozes, 1998a. p.353-368.

. 0 espaço local: âncora de desenvolvimento local. In: A reprodução social: propostas para uma gestão descentralizada. Petrópolis: Editora Vozes, 1998b. p.369-387.

FAIRCLOUGH, N. Discurso e mudança social. Brasilia: Editora UnB, 2001.

GUERREIRO RAMOS, A. A nova ciência das organizações: uma reconceituação da riqueza das nações. 2.ed. Rio de Janeiro: Editora Getúlio Vargas, 1989.

LANDER, E. Limites atuais do potencial democratizador da esfera pública não-estatal. In: BRESSER PEREIRA, L. C.; GRAU, N. C. (Org.). 0 público não-estatal na reforma do Estado. Rio de Janeiro: FGV/Clad, 1999. p.453-490.

MISOCZKY, M. C. Uma defesa da reflexão teórico-critica na pesquisa e prática da administração pública. In: ENCONTRO DE ADMINISTRAÇÃO PÚBLICA E GOVERNANÇA, 1., 2004, Rio de Janeiro. Anais... Rio de Janeiro: Anpad, 2004. 1 CD-ROM.

.; VECCHIO, R. Experimentando pensar: da fábula de Barnard à aventura de outras possibilidades de organizar. In: ENCONTRO ANUAL DA ASSOCIAÇÃO NACIONAL DOS PROGRAMAS DE PÓS-GRADUAÇÃO EM ADMINISTRAÇÃO, 28., 2004, Curitiba. Anais... Rio de Janeiro: Anpad, 2004. 1 CD-ROM.

SCHWANDT, T. A. Constructivist, interpretivist approaches to human inquiry. In: DENZIN, N. K.; LINCOLN, Y. S. Handbook of qualitative research. [S.I.]: Sage, 1994. p.118-137.

TAVARES, G. Gestão pública e transformação social no Brasil. In: HERMANS, K. (Org.). Participação cidadã: novos conceitos e metodologias. Fortaleza: Expressão Gráfica e Editora, 2004.

TELLES, V. S. Sociedade civil e a construção de espaços públicos. In: DAGNINO, E. (Org.). Anos 90, política e sociedade no Brasil. São Paulo: Brasiliense, 2004. p.91-102.

VIEIRA, L. Cidadania e controle social. In: BRESSER PEREIRA, L. C.; GRAU, N. C. (Org.). 0 público não-estatal na reforma do Estado. Rio de Janeiro: FGV/Clad, 1999. 